\title{
Youth, Creativity, and Copyright in the Digital Age
}

\section{Citation}

John Palfrey, Urs Gasser, Miriam Simun \& Rosalie Fay Barnes, Youth, Creativity, and Copyright in the Digital Age, Int'l J. Learning \& Media, Spring 2009, at 79.

\section{Published Version}

http://dx.doi.org/10.1162/ijlm.2009.0022

\section{Permanent link}

http://nrs.harvard.edu/urn-3:HUL.InstRepos:3128762

\section{Terms of Use}

This article was downloaded from Harvard University's DASH repository, and is made available under the terms and conditions applicable to Open Access Policy Articles, as set forth at http:// nrs.harvard.edu/urn-3:HUL.InstRepos:dash.current.terms-of-use\#OAP

\section{Share Your Story}

The Harvard community has made this article openly available.

Please share how this access benefits you. Submit a story.

\section{Accessibility}




\section{Youth, Creativity, and Copyright in the Digital Age}

\section{John Palfrey}

Harvard Law School

jpalfrey@cyber.law.harvard.edu

\section{Urs Gasser}

Berkman Center for Internet and Society

Harvard University

ugasser@cyber.law.harvard.edu

\section{Miriam Simun}

Digital Natives Project at the Berkman Center

Harvard University

msimun@cyber.law.harvard.edu

\section{Rosalie Fay Barnes}

Digital Natives Project at the Berkman Center Harvard University

rosalie.barnes@post.harvard.edu

Keywords

Creativity

Curriculum

Copyright law

Digital Natives

Youth

Visit IJLM.net

\section{doi: 10.1162/ijlm.2009.0022}

(c) 2009 Massachusetts Institute of Technology

Published under Creative Commons Attribution-Noncommercial-No Derivative Works 3.0 Unported license

Volume 1, Number 2

\section{Abstract}

New digital networked technologies enable users to participate in the consumption, distribution, and creation of content in ways that are revolutionary for both culture and industry. As a result, "Digital Natives"-young people growing up in the digital world with access to the technologies and the skills to use them in sophisticated ways-are now confronting copyright law on a regular basis. This article presents qualitative research conducted with students age 12-22 that explores youth understanding, attitudes, and discourse on the topic of digital creativity and copyright law. Our findings suggest that young people operate in the digital realm overwhelmingly ignorant of the rights, and to a lesser degree the restrictions, established in copyright law. They often engage in unlawful behavior, such as illegal peer-to-peer music downloading, yet they nevertheless demonstrate an interest in the rights and livelihoods of creators. Building upon our findings of the disconnect between technical, legal, and social norms as pertaining to copyright law, we present the initial stages of the development of an educational intervention that posits students as creators: the Creative Rights copyright curriculum. Educating youth about copyright law is important for empowering young people as actors in society, both in terms of their ability to contribute to cultural knowledge with creative practices and to engage with the laws that govern society. 


\section{Introduction}

Until recently, copyright was a remote legal concept to most people. Copyright laws have historically largely concerned the relatively small number of people who were content producers and distributors. That was just as well, in many respects. Copyright is an unusually complex and volatile legal doctrine, hard even for specialists to understand completely.

Today, access to a computer and an Internet connection enables anyone with even modest technical skills to create and consume content-including copyrighted content-while bypassing traditional channels of distribution. As a result, copyright laws have become relevant to the millions who interact with digital content on a regular basis. This is especially true of young people, who are the top consumers of copyrighted digital content in the United States (Madden and Lenhart 2003).

The rise and accelerated development of new technologies has left copyright law in its wake. The ease and speed with which individuals can create, consume, and disseminate digital content does not mesh well with the complex laws that regulate these behaviors in the United States and many other parts of the world. This disconnect between technological and legal allowances, in combination with a lack of knowledge about copyright law in the general public, has resulted in the emergence of a culture in which social norms surrounding the consumption and distribution of digital content have strayed far from what the law requires.

In this paper, we present original research examining youth practices and discourses surrounding creativity and copyright. We found a lack of knowledge among young people regarding the rights and restrictions inscribed in copyright law. Even when youth are aware of the illegality of their actions in consuming and sharing copyrighted content online, their behavior mostly persists. The young people we spoke with often excused their copyright-infringing actions. These findings indicate a disconnect between social norms and the law. Nevertheless, the Digital Natives we spoke with were not wholly uncritical of their own infringing practices. The young people we spoke with evinced a concern for, and an interest in, the rights of creators.

At the same time, while youth tend to have a vague knowledge of the illegality of copyright infringement, they have almost no awareness of the rights copyright law affords to users to create with copyrighted content. Fair use-the right to transform and critique cultural artifacts, or at least a defense to copyright infringement claims for having done so-is an unusually complex and vague legal doctrine. In order for Digital Natives to be empowered to exercise their rights to create and consume works in the digital domain, youth-and their teachers-must learn more about copyright law.

Our research identified the need for the support of young people in order for them to operate in legal and empowered ways in the digital world. Education is critical. Building upon our research, we have begun to develop a copyright curriculum, entitled "Creative Rights." The aim of this proposed curriculumincluded in this paper by way of example-is not simply to teach young people the workings of United States copyright law but also to help them learn about the purpose copyright law serves, the issues raised by new digital and networked technologies, and the context of the current copyright debate. We aim to teach young people how they can best take advantage of the rights and benefits the law grants them while operating legally in the digital world-and why doing so is important. Beyond issues of copyright, we hope to encourage young people to think about their individual relationship to the law. We hope that through this curriculum, learners might come to understand the role that they can have in shaping not only the culture they live in but also the laws that govern society.

\section{Exploring Youth Understandings of Copyright}

The primary finding of our research is the lack of knowledge, and corresponding level of confusion, about copyright among the Digital Natives we studied. Young people are largely confused about whether it is lawful to upload, download, stream, and remix content. Myths pervade their thinking. Many Digital Natives learn how to operate peer-to-peer sharing systems before they learn about the law. Rarely do schools teach their students the nuances of this topic, often because teachers are confused too. Social norms and the law have drifted widely apart.

To some extent, this drift is caused by the fact that the law seems unreasonable to young people. The drift is also caused by young people unaware of the illegality of their actions as they access content to which someone else holds the copyright. However, despite the general lack of understanding of copyright 
laws and the growing gap between known illegal actions and social norms, many young people do respect creators and their interests. Some Digital Natives express concern about the interests and livelihood of the artist—often resulting in intricate reasoning to justify which music they freely obtain and which they pay for. Further, youth norms concerning the reuse of the materials of others-for example, citing others' work and infringing upon their interests-are often thoughtfully formed.

\section{Copyright Law: A Brief Introduction}

Intellectual property law comprises three primary doctrinal areas: copyright, patent, and trademark. ${ }^{1}$ Copyright law is the complex set of regulations that govern expressive works. Copyright covers neither ideas (generally covered under patent) nor words and short phrases (covered by trademark law). Copyright is enshrined in the U.S. Constitution and has been built out through acts of Congress and the holdings of many courts. The edifice of present-day U.S. copyright law overlays tradition and practice that emerged under English Common Law.

Copyright law was originally established in order to spur creative production in the United States. Among other goals, copyright was intended to help create an authentic American culture (Ben-Atar 2004). Copyright today protects works "including literary, dramatic, musical, architectural, cartographic, choreographic, pantomimic, pictorial, graphic, sculptural, and audiovisual creations" (U.S. Copyright Office 2005). Since large-scale copyright reform in the 1970s, copyright protection is automatically granted to every creative work in any "fixed" form, which includes most digital works. The copyright term has been periodically extended since its inception. The original U.S. copyright term was 14 years with the privilege of renewal for another 14 years. The most recent extension provides copyright holders exclusive rights over their work for a period of the life of the author plus 70 years or in some instances 95 years from the date the work is published or 120 years from the date the work is first created (U.S. Copyright Office 2005; 17 U.S.C. § 302).

The goal of the copyright regime is to establish a balance between the private interests of creators and the public benefit of making cultural materials broadly available for use and reuse. The right to reuse existing works in specific ways, regardless of whether the existing work is held in copyright by another, is thought to be in the public interest because it perpetuates the creative cycle. Creators of new expressive works often build upon the work of previous authors-in creative works as well as in other areas of innovation. In recognition of these competing interests, the fair use doctrine operates as a check on the monopoly powers that copyright holders would otherwise enjoy over their creative output. This check is intended to enable the public to learn, criticize, parody, and otherwise reuse copyrighted materials that are part of our shared cultural heritage.

Fair use is a legal doctrine that may be invoked by someone accused of copyright infringement. The doctrine "permits a court to excuse a putatively infringing use of copyrighted material when the circumstances surrounding the use make it 'fair'" (Fisher 1988, p. 1661). The purpose of the doctrine is to limit the ability of copyright holders to apply the law in ways that stifle the very creativity the law is designed to foster (Iowa State Univ. Research Found., Inc. v. American Broad. Cos., 621 F.2d 57, 60 [2nd Cir. 1980]). Fair use "balances the public's interest in accessing and manipulating copyrighted works freely with its interest in ensuring production of creative works" (Gasser et al. 2004, p. 68). The fair use doctrine allows for legal reproduction of a copyrighted work in limited circumstances, including for purposes such as "criticism, comment, news reporting, teaching scholarship, or research" (U.S. Copyright Office 2006).

Fair uses can take many forms. One form is when a creator makes "transformative" use of the copyrighted creations of someone else. Transformative use is the appropriation of a copyrighted work in such a way that it adds something new, with a further purpose or different character, thus altering the extant work through the addition of a new expression, meaning, or message (Campbell v. Acuff-Rose Music, 510 U.S. 569, 579 [1994]). Fair use that involves the "transformation" of works is particularly crucial because it provides individuals with a legal defense (others argue that it takes the form of a "right") in their practice of criticism or parody of cultural artifacts. $^{2}$ This liberty to reuse copyrighted works, without express permission from the creator, is justified under copyright law with the understanding that transformative works provide added benefit to the public beyond that produced by the first author's work (Samuelson and Davis 2000). 
The fair use doctrine is a notoriously blurry area of copyright law. Experts sometimes joke that fair use is "the right to hire a lawyer." U.S. courts have shied away from drawing definite rules regarding its application. Fair use is nevertheless an important component of the law. In making use of this doctrine, citizens affirm their role as producers, and not simply recipients, of culture.

Fair use is not the only limitation on the rights of copyright holders. Copyright law in the United States also provides for a class of works in the public domain. These works are the cultural property of all citizens and can be used for any purpose without the original author's permission. The various copyright term extension acts have created a labyrinthine set of rules concerning the copyright status of many 20th-century works. Generally, though, any works published before 1923 have fallen into the public domain. All official publications of the U.S. government are likewise not subject to copyright protections. Works in the public domain are available with "no rights reserved" (U.S. Copyright Office 2003).

\section{Digital Developments}

Copyright law was established during the era of printing presses. In the United States, amid an information environment guarded by traditional gatekeepers, every major revision of copyright law has primarily addressed the issues facing the few and large actors in the business of producing and marketing copyrighted materials and managing the associated rights in those materials. Copyright law reform has traditionally been "the exclusive domain of corporate battles among highly trained lawyers" (Samuelson and Davis 2000).

This dynamic changed radically with the rise of digital and networked technologies. Most people in wealthy countries-where digital technologies and the skills to use them are widespread-now have the means to create and disseminate content to global audiences. Further, the development of peer-to-peer file-sharing technology, a method of distributing electronically stored information such as digital media over the Internet, has enabled any individual with Internet access to consume and share copyrighted works with unprecedented ease and speed, often without any compensation to either creators or distributors of these works.
Amid the digital revolution in creative and sharing processes, a heated debate has broken out as to whether copyright law ought to be reformed to fit better the practices of the digital era. Lawrence Lessig has argued that the law ought to be reformed so as to promote the emergence of a "free culture," one in which citizens are encouraged and supported in their efforts to remake cultural works (Lessig 2005, 2008). Lessig points also to the work of William W. Fisher III, who, along with Neil Netanel, has argued in favor of an alternative compensation system to pay creators for the use of their work through a blanket licensing system that rewards creators on the basis of pro rata enjoyment of their works (Fisher 2004; Netanel 2003). Copyright holders, by and large, have sought to strengthen existing copyright laws to provide greater protection for works in copyright and to impose higher sanctions for breaking the law, including criminal penalties.

At the same time, alternative systems of copyright licensing have emerged that build upon existing law but give creators a wider range of options for licensing their works for reuse by others. Creative Commons, a nonprofit organization, provides creators with an alternate licensing scheme that functions within the U.S. copyright system. Creative Commons licenses enable authors to treat their own creative works as common cultural resources that ought to be less regulated for a more vibrant shared production of culture. Acknowledging the historical creative practice of referencing common themes in previous works, Creative Commons aims to encourage production of culture in a collaborative fashion. In contrast to the "all rights reserved" protections of copyright, Creative Commons provides a "some rights reserved" option, offering creators a wide range of permissions that they can allow, enabling a simpler and clearer path to the collective reuse of others' works (Creative Commons [n.d.]).

The research presented here should be understood against this backdrop of instability in perceptions about what the copyright law broadly ought to look like in a digital age and in light of broad experimentation in licensing practices exemplified by the global Creative Commons movement.

\section{Methodology}

We define the group of young people we examine and learn from as "Digital Natives." While this is an 
awkward term, we embrace it because of its cultural resonance with the parents, teachers, and policymakers whom we hope to bring into a discussion of the issues raised by young peoples' use of digital technologies in their everyday lives (see Prensky 2001; Interlandi 2008; Johnson 2008; Library of Congress 2008; Rainie 2006). We define Digital Natives as a specific population within a generation of young people found around the world. These are young people born after 1980 who have grown up in a networked world and have the skills to use digital technologies. As defined in Born Digital,

[Digital Natives] are connected to each other in terms of how they relate to information, how they relate to new technologies, and how they relate to one another. When they chat with each other online, broadcast their latest videos, post messages on their blogs and social networking profiles, or share music over P2P [peer-to-peer] networks, they do so across states, national boundaries, and continents. Parallel to their digital universe, Digital Natives are embedded in regional and local customs, habits, and values. These factors, among others-together with the social and economic context and the local laws-are likely to shape the ways in which Digital Natives use digital technology, how they can realize its opportunities, and how they will address the challenges it poses. (Palfrey and Gasser 2008)

We conducted research with a socioeconomically diverse group of young people of varying technological ability. All respondents are defined as Digital Natives because of their immersion in the use of networked and digital technologies on a daily basis.

Our analysis draws on original research conducted in the greater Boston area. ${ }^{3}$ Our goal was not to undertake a comprehensive study but to take an indepth look at the way some young people are relating to information and one another on topics such as creativity and copyright, as well as to gain insight into the discourse taking place among students on issues of copyright and piracy.

Our study has a number of limitations. We explored youths' discourse on their use of digital technologies within a particular and limited population, one not representative of any larger group. In this paper we focus on the knowledge of and attitudes toward creativity, ownership, and copyright infringement among the young people with whom we spoke. The goal of our paper is to begin to uncover and describe how youth are approaching these issues and the complex dynamics at hand. We do not aim to make generalizable statements about youth perceptions of those issues at a larger scale.

For each of the following three age groups-12$13,14-18,19-22$ - we conducted three focus groups with students. Focus groups suited our investigation because we sought to gain access to youth discourse regarding issues of digital practices. We had a particular interest in how youth negotiate the emerging social norms related to new practices. The focusgroup method of investigation was particularly well suited to issues surrounding copyright law because students seemed to be at ease in discussing their behaviors, which were of varying legal standing, when in a group.

Each participant was administered a survey to obtain background information about what technologies students owned and had access to, an overview of their usage patterns and practices, and some questions to understand broadly what sorts of issues they were aware of with regard to digital technologies. Survey administration was followed by a 90-minute semistructured conversation with students about a range of issues surrounding technology use. Some students were then contacted for 60-minute one-onone follow-up interviews. Facts about the sample we explored are presented below. These descriptive statistics are meant solely to give some sense of the group included in the study. ${ }^{4}$

- $\mathrm{N}=69$;

- Ages 12-22: middle school, high school, and college students;

- $52 \%-48 \%$ female-male ratio;

- $48 \%$ white, $19 \%$ Asian, $14 \%$ black, $10 \%$ Hispanic, 9\% other;

- Range of socioeconomic standing: 79\% father college graduate, $77 \%$ mother college graduate;

- $\quad 41 \%$ first used the Internet at ages 7-9, 32\% at ages $10-12,14 \%$ at ages $3-6,14 \%$ at ages 13-15;

- $32 \%$ first shown how to use the Internet by a teacher, $29 \%$ by a parent, $8 \%$ by a friend, $10 \%$ other, $8 \%$ by a sibling, $8 \%$ don't know, $5 \%$ self; 
- $94 \%$ own a mobile phone;

- $71 \%$ own a digital camera, $95 \%$ have access to one (including on a mobile device);

- $61 \%$ own a digital video camera, $70 \%$ have access to one (including on a mobile device);

- $74 \%$ have their own computer, $98 \%$ have one in their home;

- $83 \%$ have a social networking profile, $58 \%$ logged in at least once a day;

- $3 \%$ post photos online at least once a day, $24 \%$ at least once a week;

- $3 \%$ post video online at least once a day, $11 \%$ at least once a week;

- $2 \%$ blog every day, $21 \%$ at least once a week;

- $28 \%$ download music at least once a day, $62 \%$ at least once a week;

- $15 \%$ download video at least once a day, 38\% at least once a week.

The focus-group sessions were structured with a protocol that included asking students about their experiences with digital media: their behaviors, their opinions, the role it plays in their lives, and how they negotiate specific issues and situations. While the protocol provided the basic structure of the sessions, the moderator encouraged respondent-led explorations of the topics discussed. In regard to issues of copyright law, students were prompted to answer questions about a number of themes, including downloading practices ("Who here downloads? What and how do you download? What are the pros and cons? What about legal issues?"); copyright ("Have you heard of it? What does it make you think about? What does it mean? Do you think/care/worry about it?"); ownership ("Do you use others' creations? In what ways? Do you ask permission? Why or why not? How do you decide how to proceed?"); and digital dilemmas ("Some people have made convincing arguments that music should be free online-while others say that the music industry won't be able to survive and continue providing music if people keep downloading music for free. What do you think? What are the consequences?").

These questions represent the core structure of the prompts provided to students during the focusgroup sessions. Specific issues were explored in more depth in the different groups; for example, ownership tended to be more thoroughly explored in groups whose members were more creative. We made extensive efforts to engage the youth in discussion among themselves in order to understand the opinions and negotiations occurring among youth.

\section{A Lack of Knowledge}

\section{Consumption and Distribution Practices}

Most of the young people we interviewed were confused about copyright law. Content is available on the Internet via many different modes of accessdownloading, streaming, sharing via messengers and email with friends. Content can also be copied and shared via physical format, such as burning CDs or sharing files directly from hard drive to device. The legal issues involved in this range of practices can be confusing, even to lawyers who have studied this area of law. Digital Natives' understandings of copyright law confirmed how difficult these concepts can seem to nonlawyers.

In response to the question "Do you know what 'copyright' means?" $84 \%$ of the students we talked to answered "yes." But their description of the term ranged from wholly incorrect to only partially correct. Many of the young people we spoke to confused copyright with notions of plagiarism or patent protections; for example, one high school student wrote: “[copyright is] protected by law so you can't steal ideas." Some defined copyright as though it were trademark law: "[copyright is] that someone owns that logo and you can't say that it is yours," a middle school student wrote. Overwhelmingly, definitions were heavily biased toward the rights copyright grants to original creators for financial purposes, as exemplified by another middle school student's comment, "it means that you can't sell something that's copyright."

A major concern regarding students' definitions of copyright is the lack of knowledge and understanding of allowed usage under any of the limitations and exceptions to copyright law, such as fair use. Only two out of the 69 respondents made any mention in their definitions of copyright of either reuse or creativity. Most definitions took the form of negative statements. These statements described copyright as a protection that is afforded to others, rather than a legal concept applicable to society as a whole, including young people. Consider the following answers to the question "What does copyright mean for you?"

- The property of someone else. (High school student) 
- Not to use or take that which is owned and make it your own. (High school student)

- Whatever you use without permission there is penalty. (High school student)

Young people are also confused about which actions constitute copyright infringement. Among the many possible ways of illegally obtaining copyrighted content, most young people perceived that it is illegal to practice file sharing of copyrighted works via peerto-peer networks. But even this basic fact was not universally understood. Speaking of LimeWire, a popular peer-to-peer network, some younger students in our sample explained:

R1: It's free and it's legal. It's only illegal if you put [the songs you've downloaded via Limewire] into iTunes.

R2: Yeah.

R1: Because iTunes can sue you for not paying for music but having it on there. (Middle school students)

No matter how much money [artists] make it doesn't make stealing alright and so I'm glad I don't have LimeWire stuff like that because then I would feel-like I would be unsure what to do and then-whereas, like, not having it just.... I can't steal music so I'm just going to have to like burn people's CDs or upload it to my iTunes which is legal. (High school student)

The quotations demonstrate a segment of the range of perceptions about copyright and access to digital works. Most students we spoke to understood that their own file-sharing practices on peer-to-peer networks were illegal. However, middle school students-the youngest in our small sample-were less aware than their older counterparts that this activity is illegal. Many of the young people who were aware that peer-to-peer sharing of copyrighted content is against the law would simply directly share music with friends via other methods such as email or burning a CD, incorrectly believing that this is legal. We note that such behaviors and attitudes are neither unprecedented nor unfounded: sharing music is traditionally a key activity in the socialization and identity development of adolescents (Ebare 2004), and, more generally, sharing music among friends was a widespread practice long before the digital age (see Brown, Sellen, and Geelhoed 2001).
We encountered a great deal of confusion among young people about the differences between technical allowances and legal allowances. We heard from some young people that they thought because something is technologically feasible it is also lawful to do. For example, consider the comment of one high school student in discussing the legal issues regarding the watching of streaming copyrighted content on YouTube:

R1: [Seeking to clarify the question] Is it okay that we're watching it or is it okay that

YouTube is hosting it?

MODERATOR: Both.

R1: Well, I think it must be okay that

YouTube is hosting it or else it would be shut down.

When it comes to streaming, many Digital Natives are unaware that copyrighted content that is available online on sites such as YouTube is often illegal to upload and to play. Further, when faced with this reality, young people frequently responded that they believed the liability for the streaming of content should fall on those who make the content available-not those who watch it. The exchanges we heard among students bear useful parallels to the current debates over intermediary liability, such as the one that centers on the pending lawsuit between Viacom and YouTube, in which YouTube's protection from liability for hosting user-uploaded copyrighted video content on the site is being contested.

The Digital Natives we interviewed often associate illegality, and even ethical and moral "wrongness," with infringing behavior that has clear consequences. The downloading of copyrighted content and the litigation that has followed has positioned this behavior as "wrong" (at least according to legal standards) in young people's discussions, even if they indeed continue to perpetrate these actions. Among the youth we spoke to, we found minimal critical assessment of the impact of such behavior upon artists, industry, and society. The impact largely appears not to figure into students' conception of what the law protects.

The lack of reflection on the impact of infringing copyright was often coupled, among the young people with whom we spoke, with the perception that legal enforcements being undertaken by copyright-holding industry groups are illogical. 
This clearly comes across in discussions we heard around the difference between uploading content—and thereby making it available to Internet users-and downloading content for personal use. Students regularly commented that if someone is at fault in online copyright infringement it is those "others" who initially made the content available, not those who obtain it or share the content further:

I have an illegal episode of the Boondocks, which is one of my favorite shows, on [my MySpace] page. So people who go on my page, "I want to see the Boondocks," so they go on my page and see it.... The video is on MySpace TV, and I add it to my profile. So, whoever posts the video will get in trouble, not me. (High school student)

Like everybody—if the government has a problem with people stealing music, why don't you shut down LimeWire? Why are you going after people that are downloading from the site? (High school student)

These young people speak of a sense of who ought to be responsible for the illegal activity-either the online intermediary or the government-while resisting the sense that they might also bear some responsibility in these scenarios. Growing up in a world in which so much information is readily available "for free" and where ignorance (or defiance) of copyright law is pervasive, Digital Natives often understand the free availability of content-including copyrighted content-as the norm. This understanding, when coupled with young people's largely negative reactions to what they perceive as illogical and unfair industry punishment of consumers, suggests that a generation of young people is growing up committing illegal behaviors that are perceived as acceptable. Although illegally sharing music, especially among adolescents, is not a new phenomenon, the introduction of digital technologies and global networks into music-sharing practices increases the potential harm of music sharing on the recording industry.

\section{Creative Practices}

The young people we spoke with were even more confused about the rights and defenses inscribed in copyright law than they were about its prohibitions.
Almost none of the young people we spoke with were aware of the term fair use, for instance. Compared with the youths' understandings and discourse about free consumption of others' works, their attitudes about reusing those works were often quite thoughtful regarding one's personal responsibility to the original creator. The attitudes that we encountered varied depending upon the type of content involved and the manner of the reuse. Consider the comments of the high school student below, who uses copyrighted music for the skateboarding shorts he films with friends and posts on YouTube:

I know it is kind of illegal but it is such like a small-scale thing that it is not going to matter. I am just having fun with it...it should be legal to an extent, for just like small-scale stuff that is not being sold or anything.

And that of another high school student, who participates in a video production class:

Yeah like I don't, I don't know if this is true, but I've heard that copyright laws don't apply if less than two thousand people see what you've made and if I'm just putting it on YouTube or using it on my computer then I don't really think about it ... also I think if I was a music artist and someone used my song in something they did on YouTube it must be like free publicity for my song.... Actually, I mean I really wish there weren't copyright laws. I feel like, yeah you should be able to use whatever you want because it doesn't, it seems like, especially if you're using it to kind of raise awareness about things or like, you know, as a public service announcement or yeah, depending on what you are using it for you should be able to use almost anything. Sometimes that's true though in copyright laws and sometimes it seems like it's not.

While many of the young people with whom we talked were aware of ethical dilemmas involved in using others' creations, they appeared to have little knowledge of their own legal interests in this sphere. Myths pervade their statements about the reuse of digital content. Likewise, the information they receive is largely inconsistent and confusing. The problem is not helped by the fact that traditional authority figures, such as educators and parents, often have little knowledge in this arena to permit them to 
support youth as they engage in cultural commentary and digital production online.

While many, especially older students, know that downloading copyrighted material is illegal, the differences between uploading, downloading, and streaming content are points of confusion. Further, students seemed more likely to consider an action "wrong" if they knew it might have consequences, such as a lawsuit if one were caught downloading. While we did find a lack of critical reflection on the part of some youth on how their copyright-infringing consumption activities may adversely impact others, this lack of reflection tended to be coupled with ignorance of the law and what it aims to accomplish. Further, while some youth are empowered with the technical and social knowledge to partake in creating media and influencing culture, they are largely unaware of their legal rights to do so. In order to support and encourage the potential of young people to become active participants in the creation of culture and the construction of knowledge, youth must be educated about their rights in this sphere.

\section{Disconnect between Social Norms and Law}

To understand the phenomenon of file sharing, we must understand the social norms that underlie it. Social norms function as extremely important regulators of human behavior, especially with respect to online communities (Palfrey and Gasser 2008). Because young people in particular do not have a strong formal relationship with the law, social norms exert much more sway over their behavior and can overwrite legal norms (Ellickson 1991).

Social norms of sharing copyrighted material have developed among Digital Natives despite the illegality of their actions. The Pew Internet and American Life Project found that of the 35 million Americans who downloaded music in 2003, 67 percent said that they did not care whether the downloaded music was copyrighted or not (Madden and Lenhart 2003). Among the least concerned, 72 percent were younger people between the ages of 18 and 29 (Madden and Lenhart 2003). A study by the Business Software Alliance from the same year indicated that 76 percent of the surveyed American college students believed that piracy of music or movies was acceptable in some or all instances (Business Software Alliance 2003).

Lack of knowledge and education on copyright law, its purpose, and how it functions is a major fac- tor in the widespread illegal acquisition of content by young people online. However, ignorance of the law is not the sole issue at play. Even once young people learn that a particular action is illegal—for the most part, they do learn of the illegality of downloading copyrighted content-many persist in the behavior. Violating copyright law has largely become socially acceptable, according to the Digital Natives with whom we spoke. In our research, we explored in depth this disconnect between the law and social norms and youth's perceptions of these issues.

The gap between law and social practices among youth and their ignorance of the law appear to reinforce each other. "Everyone's doing it" is an all-toocommon response among young people, including among those with whom we spoke, when they are questioned regarding the legality of their actions. Even when knowledge of the law is present, social practices and behaviors of the social group can have a significant impact on individuals' actions. Consider one high school student's comment:

Well really if they wanted to get you on like downloading illegal stuff they could, but since it's pretty much everyone in the world they can't really do anything about it.... It's not okay but everyone's doing it so I guess we're not guilty just because everyone's doing it.

This student expresses some knowledge that copyright infringement in the form of downloading content is an issue. However, the widespread practice of downloading, as well as the ease of doing it, renders the behavior acceptable for this young person. Not only is downloading often easier, less time intensive, and less costly than purchasing a recording, in the minds of many young people, it is a behavior that "everyone" engages in.

As a result of the widespread practice of online copyright infringement, especially for the younger set of Digital Natives with whom we spoke, the social norms and ignorance of the law appear to establish a cycle of unlawful behavior. Many young people learn that downloading content is illegal only after they have already learned how to download content and have engaged in the behavior for some time. Consider one middle school student's discussion of her downloading habits:

When I was like 11-yes-I had an MP3, and I didn't know LimeWire was illegal, so I didn't 
think to ask anybody, I just downloaded it. But then I started reading everything, and I found out it was illegal.

How effective might law be in curbing behavior that has already become standard practice for an 11-year-old? Perhaps if the practice were experienced as socially wrong, young people would be more open to hearing that it is illegal. For some young people, especially those who describe their parents' strong opinions on this matter, the illegality of the behavior does curb their consumption of copyrighted content. But for most, the "wrongness" of the behavior appears not to have much effect, because social norms around copyrighted content have already strayed so far from what the law dictates.

Instances in which something clearly unlawful becomes widespread practice are rare. Illegal downloading of copyrighted content is one such instance, however, and most young people with whom we spoke do not view downloading as "stealing." Much of the potential we see arising from a population of young people born digital has to do with their ease in navigating vast amounts of information; in consuming, evaluating, and reshaping this information; and in sharing it (Palfrey and Gasser 2008). That they obtain copyrighted content both legally and illegally online makes sense in this context. The discourse we heard from young people confirms this intuition. As one high school student told us, in discussing the issues of copyrighted content being hosted by YouTube:

I think it's fine. I mean I think it just makesdoes what the Internet is supposed to do, makes things more available.

In fact, some young people have come to understand free sharing of content as the norm. As one college student said:

I sort of-it sort of makes me mad how like the recording industry is being so strict and cracking down on people. Like I tend to-I don't really think there's anything morally wrong with downloading music. But I don't really do it because I'm afraid of getting caught.

The comment touches upon another key point: some young people have shied away from downloading content not because of any moral or ethical conviction and not because they wish to avoid breaking the law but because they are afraid of being caught and sued.

Consider the statement of one high school student:

I won't download an illegal thing because I'm scared I'll get sued and then my history teacher, he's really good at current news and he told us how music companies go after people who download songs and got sued. I said, whew, lucky I didn't do it.

Or the strategy of another:

I downloaded it like, illegally, but I never downloaded it to my computer because they will get you and you will owe a lot of money ...industries they'll get you for like $\$ 30,000$.

While litigation may be somewhat effective in curbing the downloading of copyrighted content, it has neither managed to convince many respondents that the behavior is wrong nor curbed their copyright infringement via other methods. As one college student commented without the slightest hint of irony: "I don't download music very much at all. I just get it from friends." For some students, confusion about copyright laws has led to a belief that content may be freely obtained so long as it is not downloaded via peer-to-peer sharing systems. Largely, the overarching norms that govern consumption practices are those of the pervasive expectation of free content that youth growing up in a digital world have come to have.

What I do a lot, and I don't know if it's like wrong or stuff, but my friend will like send me stuff over e-mail, like songs and stuff that I'll download on my iTunes. I guess that's not really bad or anything. But that's usually how I get my songs. I don't really buy my songs anymore because I don't like wasting my money on that kind of stuff. (Middle school student)

The differing methods for obtaining digital content, and the legalities associated with each method, present a confusing context for young people who daily navigate digital environments and consume digital media. Some Digital Natives with whom we spoke-those whose parents encourage and pay for legal music downloading, as well as those who seem to pride themselves on following rules in generalpay more attention than others to what may or may not be legal content consumption. 
Nevertheless, for most Digital Natives with whom we spoke, the norm of content for free is well established. Many students knowingly break the law and are not significantly concerned:

R1: I'm so used to it being free, I just can't imagine it being any other way. Like I would never pay for music now. (College student)

R2: I'd say it's socially acceptable, obviously illegal, but, you know. (College student)

In talking to young people and listening to them discuss with one another issues of copyright, downloading, and using others' creations, we can easily conclude that practices and social norms in this realm have strayed far from the law.

\section{Respecting Creators' Interests}

For a great many young people today, social norms around obtaining copyrighted content for free have fundamentally diverged from the legal standards. In the view of many young people, how they obtain such content is no longer wrong, even if it is illegal. Still, some students are careful to avoid illegally downloading music. Their reasons often have little to do with complying with the law. Although fear of getting caught-either through a record company lawsuit or by their parents-is one motivation for a few students to avoid engaging in infringing activity, another reason repeatedly arose in our interviews: respect for the creator. This view was more prominent among those students who engaged in creative activities themselves.

\section{Attitudes toward Consumption of Content}

As one middle school student described to us, not the legality of the act but the effect upon the artist kept him from illegally downloading music:

I think that people work hard on music and-I don't so much worry about that it's against the law to download it. I think that the people who are making the music deserve to earn money for making it and I guess, even though I'm saving like a dollar, I don't really feel the need to go on-look through Google for an hour to find a song or go to-I don't even remember the name of the site to download music if it takes like an hour a song.
This young person expresses the reason why she and other young people choose not to download music illegally even though social norms suggest that doing so is acceptable behavior: to compensate artists for their work. However, among the youth we spoke with, those whose parents could afford to provide prepaid access to online music services, primarily iTunes, seemed most likely to abstain from illegal music consumption.

This consideration and respect for the artist proved to be much more pervasive among youth than the fear of noncompliance with the law. However, while "hurting the artist" was generally understood to be an unacceptable act, understanding of what does and does not constitute "hurting the artist" differed among the young people with whom we spoke.

Illegal file sharing can harm the copyright holder by depriving the artist or company holding the rights of sales that otherwise would have occurred. We encountered few young people who expressed this idea during our interviews. Often, youth defended their illegal downloading practices by explaining that they are not hurting artists-who are in many young people's eyes either making too much profit or being denied profits from record sales by recording companies (in which case the illegal downloading is unlikely to hurt the artists further).

Consider the following students' comments:

Yeah, I don't know. I-like, but from what I heard about the music industry, artists don't make much money off of CD sales. It's mostly concert and like merchandise and stuff. So, I mean you're-I feel like you're not really hurting the artist as much as you're hurting the record company. (College student)

Well it depends on what you're downloading. Like if it's a local band that's not making any money I feel like I'd probably buy their CD anyways to support them, so if I download their song and then buy their CD then I'm buying their CD anyways. And then if it's someone like a big industry superstar who's making way too much money it's like, and they only have two good songs, I don't want to buy a whole $\mathrm{CD}$ for the two songs that I like. (High school student)

The tone of such comments varied among the students to whom we talked. Some young people 
earnestly described a failing recording industry. This description was coupled with a real concern for artists stemming from the industry's impending failure. Others used these issues as a justification for their illegal downloading behavior. While the apparent sincerity of claims varied, the livelihood and interests of the artists were very much present in youth discourse around downloading - suggesting that consideration for the artists has a place within the social norms Digital Natives are developing.

\section{Attitudes toward Reuse of Content}

In talking about developing norms around the reuse of others' content, respect for artists' livelihoods was very much present in the discussion. Although knowledge of fair use was almost nonexistent among the youth we interviewed, the reasoning applied by some young people as to the use of existing materials was nuanced. Largely, the young people with whom we spoke felt it was within ethical boundaries to use others' content-even without permission—in their own creations as long as they did not achieve financial gain from their creations. While this reasoning does not precisely track the law as it is today, the instinct is partially correct: two of the factors to be considered in determining fair use have to do with the nature of the use (whether commercial or noncommercial) and what effect the new work will have on the market for the original work.

One high school student who was enrolled in a graphic arts class described using a song by a popular musician, without asking permission or offering payment to the copyright holder, in a video she created:

How hard do you think it would be for, like, say I wanted to use one of Timbaland's beats for something, and I have to get his permission, how hard is it going to be for me to get his permission, you know? It's going to be so hard. And it's like I'm not going to be making any money off of this, you know.

This student is correct in assuming that to obtain a popular artists' permission for creative use of their copyrighted work is difficult, if not impossible, in most cases. Further, despite not being aware of the legal issues at hand, this Digital Native understands and considers the financial impact reuse of others' work will have upon the original creator. This reasoning will not make the student safe under the law, but the instinct offers a good place to lead into a conversation about what is lawful.

Another student described how, for videos made for fun rather than profit, using copyrighted content is fine. But when he was hired to make a video for payment, this high school student acknowledged the need to make his own music:

Well since I'm just putting it on, like-I'm not making any money off of it—so I use music from iTunes, but like right now I'm working on a skateboarding movie that I'm planning on selling at the skateboard shop in Harvard Square, so I'm going to try and either do it off of like an original soundtrack and make it all in, like, Soundtrack Pro.

The student has a sense that legality turns on the purpose to which the new work is put. This is an inaccurate reading of the copyright law. While the student might be helped by making a fair use argument as a defense to a copyright infringement claim, the mere fact that he did not profit in one instance and did in another is not dispositive. Profit, or a lack thereof, would be one of several factors that a judge would take into consideration if this case went to trial.

Despite downloading practices that seem not to have been reflected upon and an almost nonexistent knowledge of fair use, we found among young people a respect for the creator when we discussed the reuse of others' works. Although their respect was limited (and emphasized financial impact in particular), a respect for creators and their livelihoods was pervasive in the young people's discussion of the ethics of using others' creative works.

\section{Addressing Youth Understandings}

Digital Natives are growing up in a digital era. One of the hallmarks of this era is the ease of consumption, distribution, and creation of content in digital formats. With the skills and the tools to use, create, and distribute digital content on a vast scale, Digital Natives interact with copyright issues on a regular basis. Our research indicates that many young people consume, distribute, and create content without accurate knowledge of the rights, restrictions, and implications of copyright law. Further, social norms have strayed from legal ones-even when young people are aware of the illegality of their conduct, they often continue to perpetrate such behavior. And yet our findings 
suggest that Digital Natives are not wholly uncritical of their actions. We found present within youth discourse a respect for the rights and interests of creators. In order to position the next generation to take advantage of the creative, economic, and democratic opportunities enabled by digital technologies, they must be empowered to act with integrity while operating in a digital world.

Creativity should be our hook; it can help us to engage young people in considering copyright issues. By beginning with the respect young people themselves have already begun to develop for creators and their work, we can encourage Digital Natives to reflect on their infringing behaviors. By urging students to become creators and to exercise their rights to reuse and share content legally, we can position youth as creators of our culture. In encouraging young people to collaborate in transformative ways in the construction and reconstruction of our shared culture, we empower Digital Natives with the critical tools to define and redefine our media, our society, and our culture.

\section{Copyright Education for Youth}

Information, knowledge, and culture are central to human freedom and human development. How they are produced and exchanged in our society critically affects the way we see the state of the world as it is and might be; who decides these questions; and how we, as societies and polities, come to understand what can and ought to be done.

Yochai Benkler (2006)

In an environment where the malleability of digital information makes revolutionary practices of distribution and creation possible, but not necessarily legal, technology users must be informed about their responsibilities and rights with respect to digital media. The earlier in their lives that young people become knowledgeable about the legalities of the digital sphere in which they operate, the more empowered they will be to consume content with awareness and exercise their legal rights in reshaping the content created by others. These skills are quickly becoming essential aspects of what it means to be literate in a digital era (Jenkins et al. 2006; Hargittai 2007).

Curricula that are limited to the restrictions of copyright law fail not only to engage young people; they also fail to educate students in a comprehen- sive, balanced way. In an analysis of five different copyright curricula aimed at young people, Majid Yar concludes:

Particularly worrying is the ease and effectiveness with which the copyright industries have co-opted the educational system as a collaborator in (re)educating children about copyright and the ongoing attempt to mobilize parents as agents of surveillance and disciplinary correction. From a critical perspective, one must note the absence of any acknowledgement that the concept of intellectual property is itself contested and contestable, or any consideration of alternative views about how access to cultural goods might be organized. (Yar 2008, 619)

The teaching of copyright law must not simply discourage illegal use of content but must also describe the creative activities the law is designed to enable. The teaching of copyright law must both empower youth to operate legally in the digital sphere and engage them in thinking about the importance of creativity and culture in society. Young people must be taught how copyright regulations are meant to secure the very same interests of creators that Digital Natives themselves are concerned about. Further, young people must be encouraged to take an active role in the making and remaking of their own culture. Emphasis on the rights of citizens to create content using others' work empowers students to share their voice, shape their own culture, and take an active role in the construction of knowledge.

Law professor William W. Fisher III outlines the implications of the new technologies for semiotic democracy, one in which every individual has the power to shape public consciousness:

Over the course of the twentieth century, the power to make cultural meanings in most Western countries has become ever more concentrated. The increasingly dense cloud of images, sounds, and symbols through which we move is being increasingly controlled by a shrinking group of record companies, movie and television studios, advertising houses, and political consultants.... Reversing the concentration of semantic power would benefit us all. People would be more engaged, less alienated, if they had more voice in the 
construction of their cultural environment. And the environment itself ... would be more variegated and stimulating. The new technology makes that possible. (Fisher 2004, 30)

The teaching of copyright law should aspire to this engaged, connected, variegated, and stimulating society. While digital technologies provide the tools to move toward such a society, regulation has its place in balancing creators' rights and consumers' power. Rampant disregard of the law will not further the cause of greater collaboration. In order for the best potential of new technologies and the Digital Natives who use them to be realized, young people must be educated to operate legally in this realm-both in respecting others' works and in asserting their rights to contribute to the construction of knowledge.

\section{Building a Curriculum}

The data obtained in our study show that, above all, many Digital Natives are unaware of how the restrictions and liberties in copyright law apply to them and their peers. One factor leading to confusion over copyright is that it is confusing. We acknowledge the sharp limits of any form of education in such a complex area of the law. Well-trained law students at elite law schools struggle with the key concepts of intellectual property. That middle-school students and their teachers will struggle, too, is not surprising. The distinctions between downloading, streaming, or uploading copyrighted material can seem arbitrary. By correcting basic misconceptions about distinctions between types of behavior-and highlighting the ways in which there are distinctions-we can equip students with a coherent and accurate system for understanding behaviors in the context of copyright. That students understand that "copyright" is not a system of arbitrary punishment but a complex legal system is critical. By bringing teachers together with experts in the legal and digital domains to design nuanced and balanced curricula, and by using a variety of methods in the online environment, we seek to counteract the heavy-handed, extreme positions heard by young people through the mainstream media and to teach a balanced view of the law.

Copyright law is a daunting and confusing concept for young students. Many national and state teaching standards explicitly state that all graduating eighth graders should "know examples of copyright violations" and understand the "possible penalties of copyright violation" (McREL 2008). Clearly, many do not. We propose an approach to educating young people about copyright law that is grounded in the findings of our small study.

We seek to connect to students by positioning them in the role of creator-the position in the copyright dynamic for which many of them have already developed sympathy. We aim to strengthen this connection by educating youth with a pedagogical method that emphasizes the skills and knowledge young people have already gained in navigating the digital world. Engaging youth by emphasizing copyright law's relevance in their everyday lives, we propose to educate students about the rights and restrictions inherent in copyright law and the policies and procedures that dictate legal involvement in the creation, consumption, and distribution of creative works. Finally, we hope to empower young people as actors in society who are capable of contributing to cultural knowledge with creative practices and actively engaging with the laws that govern society.

\section{A Proposed Curriculum: Digital Tools for Deeper Learning}

The Creative Rights Copyright Curriculum consists of interactive learning tools that can serve as a complete or supplemental resource for the copyright and media literacy educator. We have developed prototypes of three interactive learning tools to illustrate the potential of this approach, which we describe below. The first is a fair use tool that enables students to determine whether their reuse of copyrighted content is plausibly a fair use or likely to be deemed infringing by a judge. The second is a mashup game that gives students practice in licensing creative work. The third is an interactive timeline that prompts students to look critically (and with curiosity) at the relationship between technological innovations and U.S. copyright law. The proposed curriculum also includes a case study about some of the common copyright problems that arise for users of social network sites. The case poses everyday problems in peer-to-peer sharing and prompts students to problem solve, on their own or with classmates.

We know that there is a need for real-world knowledge in the classroom (Dede et al. 2004). By educating young people who are on a daily basis engaging in practices and behavior governed by copyright law, we hope to provide them with precisely the knowledge they require to operate in critical, 
knowledgeable, ethical, and legal ways outside the classroom. The curriculum we propose aims to go beyond the concrete benefits of teaching young people the laws that govern their behavior. Imparting an understanding of how laws work is crucial to balancing the various interests within society and the role of young people as actors with respect to the laws that govern them. Further, these digital tools are designed to address the "participation gap" in youth digital literacy (Hargittai and Walejko 2008; Jenkins et al. 2006).

\section{The Scratch Case Study}

Our case study introduces students to the problems that arise when sharing creative work in social networks. The narrative focuses on a real classroom of sixth graders in St. Paul, Minnesota, who use the programming and animation platform Scratch. Scratch is a programming language developed for children that enables users to create animations, games, and graphics. It is accompanied by a website that encourages users to share their creations, remix others' creations, and work collaboratively (http://scratch.mit.edu). The case study focuses on the top two difficulties students have with sharing their work on Scratch: first, the reuse of their work without credit or acknowledgment and, second, people leaving hurtful comments about the creations of others. The case study prompts students first to work in small groups to reflect upon their personal experiences with these issues.

Students then examine Scratch's terms of use and its licensing choices, derived from Creative Commons. Students can use these pieces of information to determine if the sixth grader from Minnesota's problem of "illegal" appropriation and "rude" commen-

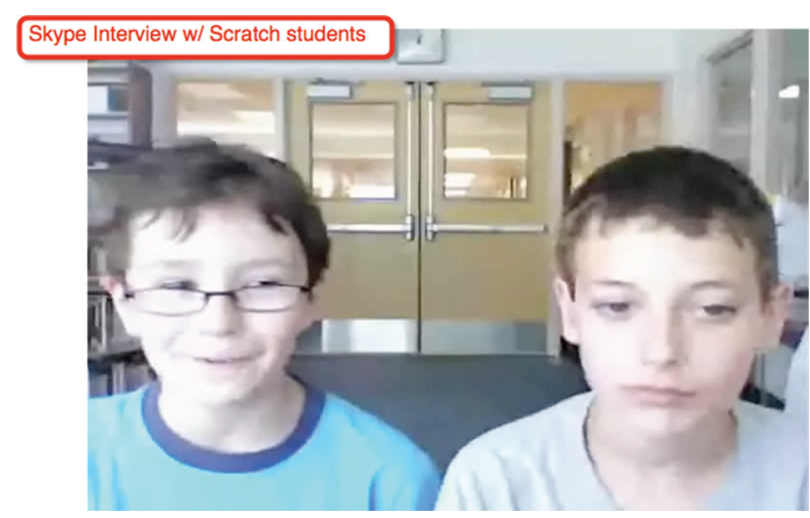

Figure 1 Alex Kreiger and Gregory Star ("The Infamous A \& G"). tary on the Scratch site is truly breaking the "laws" of the Scratch site. The students are then encouraged to brainstorm solutions to the case study's "problems."

Throughout the case study and tools, students should be encouraged to connect the problems in the narrative to their own personal experiences, both on and offline. Writing of media literacy, David Buckingham emphasizes the importance of acknowledging young people's experiences in the education process:
Adult discourses about the media may fun- damentally neglect children's experience, or at least seek to account for this in reductive ways. Giving children access to privileged dis- courses is obviously vital, but students must be encouraged to interrogate these, rather than simply reproduce them on demand. (Buckingham 1990, 224)

We should resist the temptation simply to explain the restrictions that govern students' behaviors in fields such as copyright. An acknowledgment of young people's experiences and understandings is crucial in teaching them about the law in a way that empowers them.

\section{Digital Activities: The Fair Use Tool}

The Fair Use Tool is our proposal for how to teach young people about an especially difficult area of copyright law. First, students pick a creative work that appropriates copyrighted content in some way. An example is a video found on YouTube that uses a snippet of music or an image that is copyrighted by someone else. Students then answer six multiple-choice questions about the work they have chosen. Each question is worth one point; depending on how students answer the question, the point turns green or red.

At the end of the six questions, students total their green points and their red points. If there are more green points, it looks like the use is more likely than not to be deemed "fair" by a court. If there are more red points, the use is less likely to be deemed a fair use by a court. Because it is the student, not the tool, who makes the judgment call on each question, students are likely to realize that other opinions are needed to make a good decision. Students are encouraged to work with each other to compare answers and insights on specific works. The tool provides relevant input based on court cases and sample answers in context to help scaffold the learning experience. 

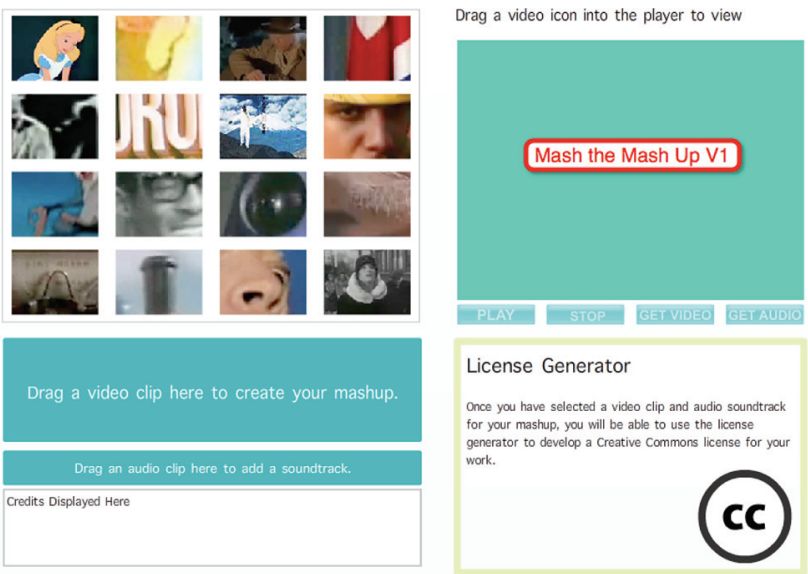

Figure 2 The Mashup game.

With practice and feedback, the notion is that both teachers and students will build an understanding of how fair use principles work in practice.

\section{Digital Activities: The Mashup Game}

The Mashup game (see figure 2) is an interactive tool that teaches students digital licensing options through the act of remixing content. The game includes content integrated into the site from the public domain, works licensed under the Creative Commons system, and exemplary fair use videos. Through drag-and-drop activities, learners explore a collection of videos. They are then prompted to mix and license their own selection of audio and video tracks.

Upon completing their creations, students are prompted to choose a license for the finished product to govern how others may use this new creation. Students must choose one of eight licensing tags, ranging from full-restriction copyright to an anonymous dedication to the public domain. In making their licensing choice, students are challenged to consider the financial implications of this decision.

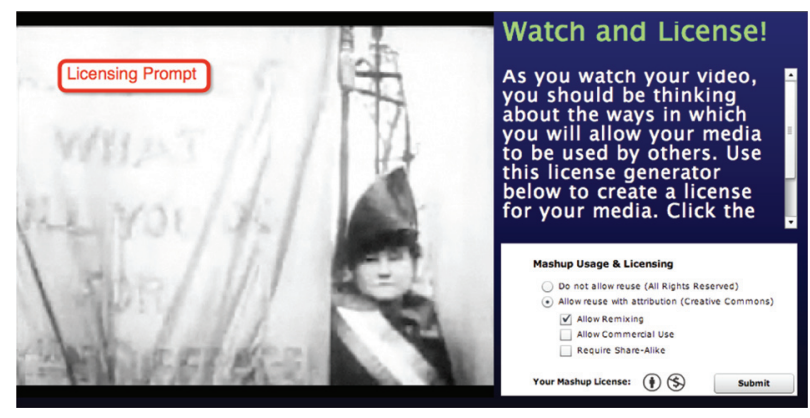

Figure 3 The Mashup game licensing prompt.
Digital Activities: The Copyright Timeline

An interactive timeline on the U.S. copyright law provides students with a visual representation of case law history (see figure 4). Built with the free Web 2.0 tool Dipity (www.dipity.com), the interactive timeline highlights the evolution of the laws that regulate copyright in conjunction with changes in technology. The timeline documents U.S. copyright law from 1790 to the present. The tool also tracks major technological innovations from the printing press to Facebook. There are three questions embedded in the timeline that ask students to think critically about the relationship between copyright and technology in the past, present, and future. Advanced students of copyright can propose additions to the timeline. By learning the history of copyright law in this way, students can come to understand the evolution of the law in relation to technology and cultural innovation.

Beyond teaching about the law as it stands today, we argue that it will be useful to inform students of the context in which copyright law was created and how it has expanded dramatically over time-and not always in direct connection with technological developments. In doing so, we can educate youth about the law and encourage them to take an active role in questioning the meaning and process of law. Students can come to understand their own important position as actors in the emerging copyright dynamic within the digital world.

\section{Legal Definitions}

We have also created simple yet accurate legal definitions for copyright, fair use, permissions, the public domain, and Creative Commons. Embedded in these definitions are links to further resources, media links, and research tools. The legal definitions are primarily for teachers who wish to learn more about each topic and its related resources, but students are welcome to visit them as well.

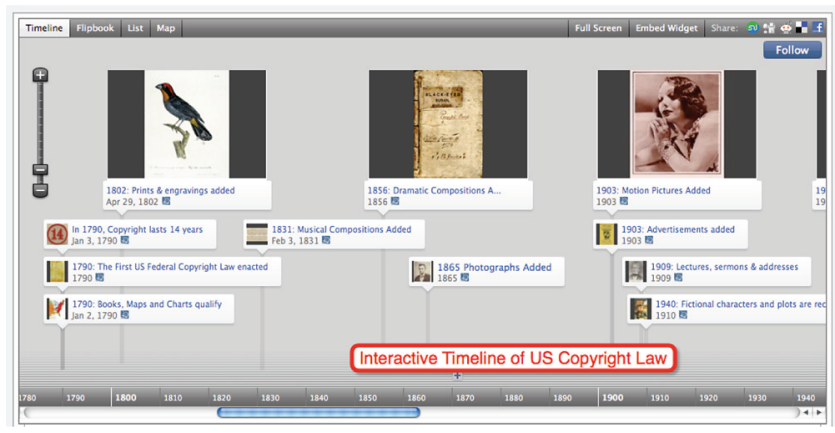

Figure 4 Interactive timeline of U.S. copyright law. 


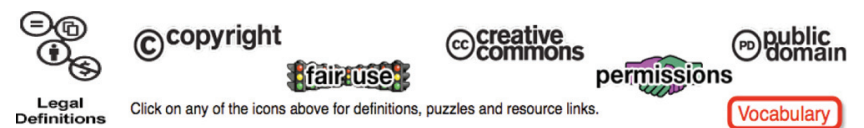

Figure 5 Legal definitions for copyright, fair use, permissions, the public domain, and Creative Commons.

\section{The Creative Rights Copyright Curriculum}

The Creative Rights Copyright Curriculum is fully interactive. As a backup, PDFs are provided wherever possible to ensure access for those with low-bandwidth connections who may wish to use the materials in an offline manner. The proposed curriculum is intended to highlight the choices inherent in copyright law, to engage students to create licenses for their own work, and to bring commonplace, real-life digital dilemmas into the classroom. Our goal should be to educate youth about the options available to them as creators and the roles they may come to play through their own learning and creative practices.
Blogging

Students' continued participation is recommended in the optional blogging section of the website. Students can submit media of any form to be considered for posting on the blog once permissions have been cleared, the fair use test passed (if applicable), and the student media licensed under Creative Commons or default (full) copyright protection. Vetted work will be regularly posted along with brief commentary related to the licensing or fair use decisions of the creator. Students and teachers can browse the blog to find exemplary forms of creative work, fair use, and licensing decisions. Through the Creative Rights blog, young and exceptional artists are highlighted, providing real-life examples for learners, encouraging creative participation, and enabling students to learn from the larger community.

\section{Time Commitment, Assessments, and Educators' Guides}

The curriculum is designed to last anywhere from 20 to 120 minutes, depending on how the teacher

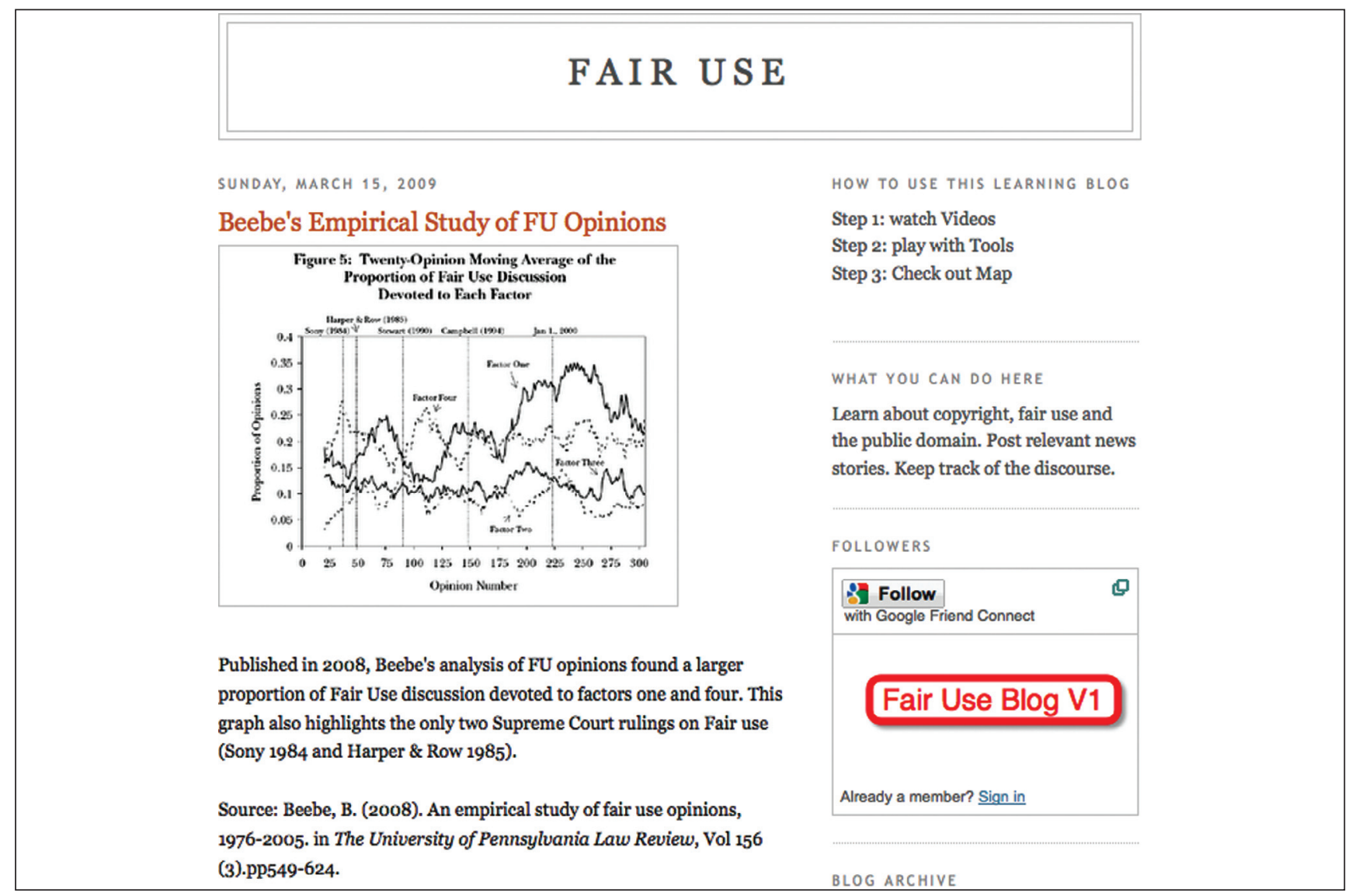

Figure 6 Blogging section of the website. 
chooses to navigate the resources. Each unit of activity is self-contained and also builds upon the previous section. An educator's guide exists on the website and in PDF format. The website guide includes video of teachers using the curriculum in their lessons. Each activity houses a battery of assessments. Educators can use their discretion in selecting or creating the appropriate measurements.

\section{The Curriculum in All Its Parts}

The Creative Rights curriculum comprises an online presence, video tutorials, interactive activities, legal definitions, blogs, and an educator's guide. This curriculum is intended to highlight the choices inherent in copyright and fair use law; it engages students to create licenses for their own work; and it aims to enable students to make better and more-informed choices about their use of copyrighted materials. By learning about the full range of licensing options available to them as creators, young people can begin to put this knowledge into practice, whether their inclination is to share freely, restrict access fully, or choose a course somewhere in between.

\section{Conclusions and Future Directions}

The current controversies involving copyright and digital technology present an opportunity for reassessment of how we teach about creativity in schools. Today, Digital Natives navigate the online environment with varying degrees of ignorance and a diverse range of misunderstandings of copyright law. Despite the jarring differences between youth practices and legal allowances, our research has shown that young people do have concern for the rights and interests of creators.

We suggest that education, rather than litigation, is the best way to bridge these gaps and reforge connections between creative industries and their young consumers (Palfrey and Gasser 2008). No single intervention could possibly solve the problems to which copyright's complexity and volatility give rise at this moment in history. Short of simplifying the law, education is the most promising way forward. Digital Natives must be empowered to operate knowledgeably and critically in a world in which they increasingly possess the skills needed to disseminate and transform easily obtainable content.

We center our own proposed educational intervention on the idea of positioning students as cre- ators who can play an active role in shaping culture and have the legal support to do so. We propose to challenge students to consider the dynamics at play in consuming, creating, and licensing contentincluding personal reflection on how their actions may affect others. Finally, we hope that by educating students, as well as teachers, about copyright law in ways that empower them to create and share their voice with others we will empower young people to take an active, meaningful role vis-à-vis the laws that govern our society.

\section{Acknowledgments}

The authors gratefully thank research and production team members John Randall, Meg Moore, Ilan Goldbard, Chris Spence, Jacob Kramer-Duffield, Nikki Leon, Rebecca Rojer, Matt Landry, Conor Shankman, Paulina Villarroel, Joe Douillette, Carey Anderson, Rebecca Tabasky, and Seth Young for their assistance along the way. The authors gratefully thank David Ardia and Sam Bayard of the Citizen Media Law Lab; Phil Malone of the Cyberlaw Clinic; Lewis Hyde; and Chris Bavitz and Terry Fisher for their legal counsel and expertise. Thanks also to Martha Stone Wiske, Chris Dede, David Rose, Ilona Holland, and David Dockterman of the Harvard Graduate School of Education for their feedback and guidance. The authors gratefully thank Karen Randall's classroom of Scratch students: Will: Bigred466; Alec: ellielli; Gregory: masterock; Alex: ahansonrosenberg001; Kate: opey6; Evette: Magicalluv4kitties; Gavin: EggHead. Thank you to Eszter Hargittai, Charles Nesson, James Thurman, and Melanie Dulong de Rosnay for commenting on drafts of this article and to all the participants in a research workshop on this topic in Switzerland in May 2008 and in Cambridge in February 2009. The authors also thank the John D. and Catherine T. MacArthur Foundation, Harvard University, and the Microsoft Corporation for research support that assisted in the development of this work. All errors and omissions are the authors' alone.

\section{Notes}

1. Some experts might add trade secret as a fourth primary doctrinal area of intellectual property law.

2. See, for example, the Electronic Frontier Foundation's discussion of this issue ("Is Fair Use a Right or Merely a Defense?"). Professor Charles Nesson has also asserted this argument in the context of defending Joel Tenenbaum in District Court and First Circuit Court of Appeals proceedings on allegations of illegal file-sharing. The Tenenbaum case has been consolidated into Capital Records, Inc. et al v. Alaujan, Dkt. No. 1:03-cv-11661NG in the U.S. District Court for the Eastern District of Massachusetts.

3. Respondents were recruited via educators and administrators at the middle school, high school, after school, and university levels. Particular effort was made to obtain a diverse group of respondents with regard to 
socioeconomic status, as well as inclination toward participating in creative activity online.

4. Some percentages may exceed 100 percent due to rounding.

\section{References}

Ben-Atar, Doron S. 2004. Trade secrets: Intellectual piracy and the origins of American industrial power. New Haven: Yale University Press.

Benkler, Yochai. 2006. The wealth of networks. New Haven: Yale University Press.

Brown, Barry, Abigail Sellen, and Erik Geelhoed. 2001. Music sharing as a computer supported collaborative application. In ECSCW 2001: Proceedings of the seventh European Conference on Computer Supported Cooperative Work, edited by Wolfgang Prinz, Matthias Jarke, Yvonne Rogers, Kjeld Schmidt, and Volker Wulf, 179-198. Dordrecht, Netherlands: Kluwer Academic Publishers.

Buckingham, David. 1990. Watching media learning: Making sense of media education. Bristol, UK: Falmer Press.

Business Software Alliance. 2003. Internet piracy on campus. http://www.bsa.org/country/Research\%20and\%20Statistics/ /media/80B03498709F4B7E93E6B2D449795763.ashx (accessed August 4, 2008).

Creative Commons. [n.d.] About. http://creativecommons .org/about/ (accessed July 31, 2008).

Dede, Chris, T. Brown-L'Bahy, D. Ketelhut, and P. Whitehouse. 2004. Distance learning (virtual learning). In The Internet encyclopedia, edited by Hossein Bidgoli, 549-560. New York: John Wiley and Sons.

Ebare, Sean. 2004. Digital music and subculture: Sharing files, sharing styles. First Monday 9 (2). http://firstmonday .org/htbin/cgiwrap/bin/ojs/index.php/fm/article/view/ 1122/1042 (accessed April 1, 2009).

Electronic Frontier Foundation. 2002. Fair use frequently asked questions (and answers). http://w2.eff.org/IP/ eff_fair_use_faq.php (accessed May 12, 2009).

Ellickson, Robert C. 1991. Order without law: How neighbors settle disputes. Cambridge, MA: Harvard University Press.

Fisher, William. 1988. Reconstructing the fair use doctrine. Harvard Law Review 101:1659-1795.

Fisher, William. 2004. Promises to keep. Stanford, CA: Stanford University Press.

Gasser, Urs, John Palfrey, Derek Slater, et al. 2004. iTunes: How copyright, contract, and technology shape the business of digital media-a case study. Research Publication no. 2004-07. Berkman Center for Internet and Society, Harvard Law School. http://ssrn.com/abstract=556802 (accessed April 13, 2009).

Hargittai, Eszter. 2007. A framework for studying differences in people's digital media uses. In Cyberworld unlimited, edited by Nadia Kutscher and Hans-Uwe Otto, 121-137. Wiesbaden, Germany: VS Verlag für Sozialwissenschaften/GWV Fachverlage GmbH.

Hargittai, Eszter, and Gina Walejko. 2008. The participation divide: Content creation and sharing in the digital age. Information, Communication and Society 11 (2):239-256.

Interlandi, Jeneen. 2008. Reading this will change your brain. Newsweek, October 14. http://www.newsweek .com/id/163924 (accessed April 1, 2009).
Jenkins, Henry, Katie Clinton, Ravi Purushotma, Alice J. Robison, and Margaret Weigel. 2006. Confronting the challenges of participatory culture: Media education for the 21st century. Chicago: MacArthur Foundation. http:// digitallearning.macfound.org/atf/cf/\%7B7E45C7E0 -A3E0-4B89-AC9C-E807E1B0AE4E\%7D/JENKINS _WHITE_PAPER.PDF (accessed August 4, 2008).

Johnson, Steve. 2008. Dawn of the digital natives. Guardian, February 7. http://www.guardian.co.uk/technology/ 2008/feb/07/internet.literacy (accessed April 1, 2009).

Lessig, Lawrence. 2005. Free culture: The nature and future of creativity. New York: Penguin.

Lessig, Lawrence. 2008. Remix: Making art and commerce thrive in a hybrid economy. New York: Penguin.

Library of Congress. 2008. Digital Natives lecture series. News from the Library of Congress. April 23. http://www.loc.gov/ today/pr/2008/08-057.html (accessed April 1, 2009).

Madden, Mary, and Amanda Lenhart. 2003. Music downloading, file-sharing and copyright. Washington, DC: Pew Research Center. http://www.pewinternet.org/Reports/2003/ Music-Downloading-Filesharing-and-Copyright.aspx (accessed April 13, 2009).

McREL: Mid-continent Research for Education and Learning. 2008. Technology strand. In Content knowledge standards and benchmark database. Denver: McREL. http:// www.mcrel.org/compendium/topicsDetail.asp?topicsID $=138 \&$ subjectID=19 (accessed August 1, 2008).

Netanel, Neil W. 2003. Impose a noncommercial use levy to allow free peer-to-peer file sharing. Harvard Journal of Law and Technology 17 (1):1-84.

Palfrey, John, and Urs Gasser. 2008. Born digital: Understanding the first generation of digital natives. New York: Basic Books.

Prensky, Mark. 2001. Digital natives, digital immigrants. On the Horizon 9 (5). http://www.marcprensky.com/ writing/Prensky\%20-\%20Digital\%20Natives ,\%20Digital\%20Immigrants\%20-\%20Part1.pdf (accessed April 13, 2009).

Rainie, Lee. 2006. Digital "natives" invade the workplace. Pew Internet and American Life Project, September 28. http://pewresearch.org/pubs/70/digital-natives-invade -the-workplace (accessed April 1, 2009).

Samuelson, Pamela, and Randall Davis. 2000. The digital dilemma: A perspective on intellectual property in the information age. Paper presented at the 28th Annual Telecommunications Policy Research Conference, Arlington, VA.

U.S. Copyright Office. 2003. Certain unpublished, unregistered works enter public domain. http://www.copyright .gov/pr/pdomain.html (accessed August 14, 2008).

U.S. Copyright Office. 2005. United States Copyright Office: A brief introduction and history. http://www.copyright .gov/circs/circ1a.html (accessed August 22, 2008).

U.S. Copyright Office. 2006. Fair use. http://www.copyright .gov/fls/fl102.html (accessed August 14, 2008).

Yar, Majid. 2008. The rhetorics and myths of "anti-piracy" campaigns: Criminalisation, moral pedagogy and capitalist property relations in the classroom. New Media and Society 10 (2):605-623. 